\title{
MENINGKATKAN KEMAMPUAN SPASIAL MATEMATIS SISWA DENGAN MODEL PEMBELAJARAN PROBLEM BASED LEARNING BERBANTUAN GEOGEBRA
}

\author{
Rani Sugiarni $^{1}$, Egi Alghifari², Ayuni R. Ifanda ${ }^{3}$ \\ ${ }^{1}$ Universitas Suryakancana \\ ranisugiarni@gmail.com \\ ${ }^{2}$ Universitas Suryakancana \\ egi_alghifari@yahoo.com \\ ${ }^{3}$ Universitas Suryakancana \\ aikarizka6@gmail.com
}

\begin{abstract}
ABSTRAK
Kemampuan spasial santri di pesantren MA Al-Hanif sangat rendah. Hal ini disebabkan karena para santri jarang menggunakan media pembelajaran matematika yang membantu proses pembelajaran. Media pembelajaran yang mampu membantu daya bayang diantaranya media geogebra. Penelitian ini bertujuan untuk mengetahui peningkatan kemampuan spasial matematis siswa dengan model pembelajaran problem based learning berbantuan geogebra. Metode penelitian menggunakan Penelitian Tindakan Kelas yang dilaksanakan dalam 3 siklus tindakan. Popolasi dalam penelitian ini adalah santri kelas XI MA Al-Hanif Cibeber tahun ajaran 2016-2017, sampel pada penelitian ini sebanyak 17 orang dengan materi Geometri. Instrumen yang digunakan adalah soal tes kemampuan spasial pada tiap siklus, lembar observasi guru dan siswa dalam pembelajaran dan angket sikap siswa. Hasil penelitian menunjukan bahwa dengan menerapkan model pembelajaran problem based learning berbantuan geogebra dapat meningkatkan kemampuan spasial para santri. Hal ini ditunjukan dengan hasil tes kemampuan spasial setiap siklusnya. Pada tindakan siklus I daya serap klasikal santri menacapai $53 \%$, tindakan siklus II naik daya serap klasikal santri $76 \%$ dan tindakan siklus III hampir $82 \%$ daya serap klasikal mengalami peningkatan dari hasil penelitian tersebut disimpulkan bahwa model pemebelajaran problem based learning berbabtuan geogebra dapat meningkatkan kemampuan spasial para santri. Selain itu, aktivitas siswa dan guru dengan model Problem based Learning berbantuan Geogebra dapat berjalan dengan efektif dan kondusif. Respon siswa dalam pembelajaran geometri dengan model Problem based Learning berbantuan Geogebra umumnya menghasilkan kesan yang positif.
\end{abstract}

Kata Kunci : Kemampuan Spasial, Problem based Learning, Geogebra.

\begin{abstract}
Students' spatial ability of MA Al-Hanif is very low. This is because the students rarely use mathematics learning media which helps learning process. One of learning media that can help imagination is Geogebra. This study aims to determine the improvement of mathematical spatial abilities of students with problem-based learning model assisted with Geogebra. The research method used is Classroom Action Research which implemented in 3 action cycles. Population in this study is
\end{abstract}


students of class XI MA Al-Hanif in academic year 2016-2017, with sample as many as 17 people with Geometry course. The instrument used a matter of spatial ability test in each cycle, teacher and student observation sheet used in learning and student attitude questionnaire. The results showed that, by applying the learning model of problem-based learning problem assisted geogebra can improve spatial ability of the students. This is shown by the results of spatial ability tests in each cycle. In the cycle I, the classical absorption of students reaches $53 \%$, the second cycle action goes up the classical absorption of $76 \%$ students and the third cycle action almost $82 \%$ of the classical absorption increases from the results of the study concluded that the problem-based learning model assisted geogebra can improve the students' spatial ability. Furthermore, student and teacher activity toward geogebra assisted Problem-Based Learning model went run effectively and conducive. The response of students in geometry learning with Geogebra assisted problem-based learning model generally produces a positive impression.

Keywords: Spatial Ability, Problem Based Learning, Geogebra.

Format Sitasi: Sugiarni, R., Alghifari, E., \& Ifanda, R.A. (2018). Meningkatkan Kemampuan Spasial Matematis Santri Madrasah Aliyah dengan Model Pembelajaran Problem Based Learning Berbantuan Geogebra. KALAMATIKA Jurnal Pendidikan Matematika, 3(1), 93-102.

Penyerahan Naskah: 19 Mei 2017 || Revisi: 28 Agustus 2017 || Diterima: 2 Oktober 2017

\section{PENDAHULUAN}

Perkembangan teknologi yang semakin maju mengakibatkan Indonesia ikut serta dalam mengembangkan teknologi agar tidak kalah bersaing dengan negara-negara maju lainnya termasuk dalam mengembangkan teknologi dalam dunia pendidikan. Dalam hal ini yang mengembangkan teknologi dalam pendidikan tentunya guru di sekolah terhadap peserta didiknya dalam mendapatkan ilmu. Dalam hal ini semua sekolah harus mengembangkan teknologi termasuk sekolah berbasis pesantren. Pengembangan teknologi dilakukan pada semua mata pelajaran dan guru harus bisa mengembangkan teknologi termasuk matematika.

Matematika merupakan disiplin ilmu yang membutuhkan pemikiran tinggi. Konsep matematika tersusun dari konsep yang paling sederhana sampai yang paling sulit. Hal lain konsep matematika juga secara pasti, logis, tersusun, dan sistematis mulai dari konsep yang paling sederhana sampai pada konsep yang paling kompleks. Sifat-sifat atau teori-teorinya dianut secara deduktif, maksudnya proses pencarian kebenarannya lain dengan ilmu pengetahuan lain yang menggunakan metode induktif. Dengan karakteristik-karakteristik tersebut, matematika disebut sebagai ratunya ilmu, yaitu matematika sebagai sumber dari ilmu lain (Karso, 1993). 
Kebanyakan para siswa yang merasa kesulitan mempelajari pembelajaran matematika terutama dalam hal kemampuan spasial hal ini terbukti dari hasil observasi di salah satu pesantren di cianjur yang kemampuan spasialnya rendah diakibatkan guru dan fasilitas sekolah yang kurang dalam mengembangkan teknologi dan media pembelajaran sehingga santri mengalami kemampuan spasial matematika yang rendah. Matematika sebagai salah satu pelajaran yang sulit untuk dibayangkan hanya dengan kata-kata, matematika memerlukan adanya media penunjang untuk memudahkan pengkomunikasian dalam pembelajarannya. Dari hasil analisis penelitian (Mulyadi, Riyadi, \& Subanti, 2015) bahwa persentase kesalahan terbesar siswa dalam kemampuan spasial matematika adalah siswa sulit dalam mentrasformasi dan memberikan kesimpulan akhir dalam objek geometri. Selain itu kurangnya imajinasi untuk memvisualisasikan komponen-komponen bentuk bangun ruang sehingga siswa mengalami kesulitan dalam mengkonstruksi bangun ruang dan menyelesaikan masalah (Siswanto, 2016). Penelitian lainnya (Syahputra, 2013) menunjukkan bahwa pendekatan pembelajaran matematika realistik pada topik geometri dengan bantuan komputer program Cabri 3-D dapat meningkatkan kemampuan spasial siswa di sekolah berkategori baik dan sedang. Pada kemampuan spasial tinggi persentase kesalahan terbesar adalah kesalahan transformasi dan kesalahan kesimpulan.

Kemampuan spasial matematis adalah kemampuan membayangkan, membanding, menduga, menentukan, mengonstruksi, memperesentasikan, dan menemukan informasi dari stimulus visual dalam konteks ruangan. Kemampuan ini menuntut indikator siswa untuk bisa menyatakan kedudukan antar unsur- unsur suatu bangun ruang, mengidentifikasi dan mengklarifikasi gambar geometri, membayangkan bentuk atau posisi suatu objek geometri yang dipandang dari sudut pandang tertentu, mengonstruksi dan merepresentasikan modelmodel geometri yang digambar pada bidang datar dalam konteks ruang, dan menginvestigasi suatu objek geometri (Lestari \& Yudhanegara, 2015).

Salah satu alternatif dalam menyelesaikan masalah matematika dalam kemampuan spasial matematika para santri dengan model pembelajaran problem based learning yang dibantu dengan media pembelajaran visual Geogebra agar para santri bisa lebih memahami materi geometri yang diajarkan.

Model pembelajaran problem based learning sesuai dengan kondisi siswa dengan kehidupan sehari-hari dan kurikulum 2013 yang sedang berlaku. Hasil penelitian (Sugiarni, 
2015) pencapaian serta peningkatan kemampuan pemecahan masalah matematik siswa yang mendapat asesmen kinerja dalam problem based learning lebih baik daripada siswa yang mendapat pembelajaran konvensional. Kondisi ini memberikan gambaran bahwa asesmen kinerja dalam problem based learning sangat berpengaruh terhadap pencapaian serta peningkatan kemampuan pemecahan masalah matematis siswa. Penelitian yang lain (Aisyah, 2016) hasil penelitian yang diperoleh nilai rerata kemampuan pemecahan masalah matematika peserta didik kelompok eksperimen yang diajar menggunakan model problem based learning berbantuan software geogebra lebih tinggi daripada nilai rerata kemampuan pemecahan masalah matematika peserta didik kelompok kontrol yang diajar menggunakan model pembelajaran kooperatif tipe think pair share.

Model pembelajaran problem based learning dengan pendekatan saintifik. Pendekatan saintifik berasal dari kata sains yang berarti ilmu. Maka, pendekatan saintifik pendekatan keilmuan yang bersifat logis dan sistematis (Permatasari, 2014). Sedangkan Problem Based Learning merupakan model pembelajaran yang menghadapkan siswa pada masalah sehingga siswa dapat mengembangkan kemampuan dalam berpikir tingkat tinggi dan keterampilan dalam menyelesaikan masalah serta memperoleh pengetahuan baru terkait dengan permaslaahan tersebut (Lestari, dan Yudhanegara, 2015). Sementara media penunjang yang digunakan adalah Geogebra. Menurut Hohenwarter Geogebra adalah program komputer untuk membelajarkan matematika khususnya geometri dan aljabar. Geogebra sangat bermanfaat sebagai: 1) media demonstrasi dan visualisasi; 2) alat bantu konstruksi; 3) alat antu proses penemuan; dan 4) alat komunikasi dan representasi (Nopiyani, Turmudi \& Prabawanto, 2018).

Tahapan problem based learning yang digunakan dalam pembelajaran meliputi beberapa fase pembelajaran diantaranya : 1) Fase Orientasi yakni mengorientasikan siswa terhadap masalah dunia nyata; 2) Fase Engagement, yakni siswa terlibat dalam aktivitas menyelesaikan masalah; 3) Fase Inquiry and Investigation, yakni siswa melakukan penyelidikan dan investigasi dalam rangka menyelesaikan masalah; dan 4) Debriefing, yakni siswa melakukan tanya jawab dan diskusi terkait kegitan penyelesaian masalah yang dilakukan (Lestari \& Yudhanegara, 2015).

Berdasarkan uraian di atas, penulis mengadakan penelitian yang bertujuan untuk meningkatkan kemampuan spasial siswa khususnya para santri dalam pembelajaran 
matematika dengan model pembelajaran Problem Based Learning berbantuan Geogebra, melihat aktivitas siswa/santri dan guru dalam model pembelajaran Problem Based Learning berbantuan Geogebra, dan melihat sikap siswa terhadap model pembelajaran Problem Based Learning berbantuan Geogebra.

\section{METODE PENELITIAN}

Metode penelitian Penelitian Tindakan Kelas (Classroom Action Research) yang merupakan bentuk kajian yang bersifat refleksi oleh pelaku tindakan yang ditujukan untuk meningkatkan kemampuan spasial matematis siswa, secara sengaja dilakukan selama pembelajaran. Penelitian tindakan kelas merupakan proses pengkajian masalah pembelajaran didalam kelas melalui berbagai tindakan yang telah direncanakan dalam situasi yang nyata serta menganalisis setiap pengaruh dari perlakuan tersebut.

Model penelitian yang digunakan pada penelitian ini berbentuk siklus-siklus yang merupakan metode yang dikembangkan oleh Kemmis dan Mc. Taggart, meliputi perencanaan (planing), aksi atau tindakan (acting), observasi (observing), dan refleksi (reflecting) (Aqib, 2006). Penelitian ini terdiri dari tiga siklus dan tiga kali tes yang bertujuan untuk mengetahui perkembangan kemampuan spasial matematis siswa dalam pembelajaran Problem Based Learning berbantuan Geogebra.

Penelitian tindakan kelas ini di MA Al-Hanif Cibeber dengan subjek penelitian tindakan kelas yang akan dilakukan yaitu pada siswa kelas XI IIS tahun ajaran 2016-2017 dengan materi Geometri. Teknik pengumpulan data dalam penelitian ini dilakukan dengan cara menentukan terlebih dahlu smber data, jenis data, instrumen yang digunakan dan teknik pengumpulannya. Secara lengkap teknik pengumpulan data yang akan dilakukan oleh peneliti akan dijelaskan pada tabel berikut:

Tabel 1. Teknik Pengumpulan Data

\begin{tabular}{llll}
\hline $\begin{array}{c}\text { Sumber } \\
\text { Data }\end{array}$ & \multicolumn{1}{c}{ Jenis Data } & $\begin{array}{c}\text { Instrumen } \\
\text { yang } \\
\text { Digunakan }\end{array}$ & $\begin{array}{c}\text { Teknik } \\
\text { Pengumpulan } \\
\text { Data }\end{array}$ \\
\hline Siswa & $\begin{array}{l}\text { Kemampuan Spasial } \\
\text { Matematis }\end{array}$ & Perangkat tes & $\begin{array}{c}\text { Tes pada siklus I, II, } \\
\text { dan III } \\
\text { Observasi }\end{array}$ \\
Guru dan & $\begin{array}{l}\text { Aktivitas siswa dan guru } \\
\text { Siswa }\end{array}$ & $\begin{array}{l}\text { Lembar observasi } \\
\text { guru dan siswa }\end{array}$ & \\
pembelajaran dalam & Angket & $\begin{array}{c}\text { Penyebaran angket di } \\
\text { kelas }\end{array}$ \\
& $\begin{array}{l}\text { Respon siswa terhadap } \\
\text { pembelajaran Problem } \\
\text { Based Learning berbantuan } \\
\text { Geogebra }\end{array}$ & & \\
\hline
\end{tabular}


Pada Tabel 1. terdapat sumber data dalam penelitian yang terdiri dari beberapa sumber yaitu siswa/santri yang berfungsi sebagai subjek penelitian untuk mendapatkan data tentang hasil belajar dan kemampuan spasial matematis siswa. Sedangkan guru berfungsi untuk melihat tingkat keberhasilan implementasi model Problem based Learning dan aktivitas siswa dalam proses pembelajaran. Angket dan wawancara berfungsi untuk mengetahui respon siswa yang menunjukkan suasana belajar dan komentar siswa dalam pembelajaran matematika dengan model Problem based Learning berbantuan Geogebra. Sementara penganalisisan kemampuan spasial siswa diperoleh dari hasil jawaban siswa pada setiap siklus.

\section{HASIL DAN PEMBAHASAN}

\section{Kemampuan Spasial Matematis}

Pembelajaran matematika dengan menggunakan pembelajaran model Problem Based Learning berbantuan Geogebra memudahkan siswa dalam membayangkan berbagai bentukbentuk geometri dalam kehidupan sehari-hari melalui masalah-masalah yang tersaji.

Tingkat spasial siswa pada tiap siklus dapat disimpulkan bahwa presentase tingkat spasial siswa menunjukkan adanya peningkatan pada siklusnya. Di siklus I sebagian besar siswa bisa membayangkan maksud tiap soal tes siklus I. Pada siklus ke II hampir semua siswa sudah bisa membayangkan dengan lebih tepat tiap soal tes siklus II, dan pada umumnya kemampuan spasial siswa telah meningkat. Sementara untuk presentase siswa yang memiliki kemampuan spasial rendah mengalami penurunan pada tiap siklusnya. Untuk lebih jelasnya bisa dilihat di tabel berikut.

Tabel 2. Data Hasil Tes Siklus

\begin{tabular}{lrcc}
\hline Data & Siklus I & Siklus II & Siklus III \\
\hline Siswa Tuntas & 9 & 13 & 14 \\
Nilai Terendah & 20 & 30 & 40 \\
Nilai Tertinggi & 100 & 100 & 100 \\
Nilai Rata-rata & 64 & 86 & 88 \\
Daya Serap Klasikal & $53 \%$ & $76 \%$ & $82 \%$ \\
\hline
\end{tabular}

Dari tabel 2. terlihat bahwa dari siklus I sampai siklus III nilai siswa mengalami peningkatan. Hal ni terlihat dari meningkatnya ketuntasan, dan Daya Serap Klasikal (DSK), kemudian didukung dengan sikap siswa yang antusias dalam pembelajaran. Nilai spasial matematis tertinggi mencapai nilai sempurna dan untuk nilai terendah mengalami peningkatan menuju lebih baik untuk setiap siklusnya. Dengan demikian dapat disimpulkan bahwa 
penerapan pembelajaran geometri dengan pendekatan saintifik model Problem Based Learning berbantuan Geogebra dapat meningkatka kemampuan spasial matematis siswa.

\section{Aktivitas Siswa dan Guru}

Selain melihat peningkatan kemampuan spasial matematis siswa, peneliti juga melihat bagaimana suasana pembelajaran model Problem based Learning berbantuan Geogebra berlangsung. Hal ini dilihat dari hasil aktivitas siswa dan guru pada setiap siklusnya yang mengalami peningkatan dan termasuk pada kategori baik pada setiap pertemuan.

Dari hasil observasi siswa pada siklus I, siswa yang tuntas sebanyak 9 orang dari 17 orang. Peneliti berusaha untuk meningkatkan suasana belajar siswa agar menyenangkan dan lebih bisa merangsang kemampuan spasial siswa pada pertemuan selanjutnya. Adanya peningkatan pada siklus II dengan jumlah siswa yang tuntas sebanyak 13 orang merupakan peningkatan yang dikarenakan siswa telah terbiasa pada pembelajaran yang diterapkan di kelas. Terlihat pada saat pembelajaran berlangsung siswa antusias dalam bertanya, menjawab dan mempresentasikan hasil jawabannya di depan kelas. Pada hasil observasi aktivitas siswa siklus III juga mengalami peningkatan dengan jumlah siswa tuntas sebanyak 14 orang dari 17 orang. Dengan demikian dapat disimpulkan bahwa pembelajaran geometri yang berlangsung selama tiga siklus ini berjalan dengan baik.

\section{Respon Siswa Terhadap Model Problem based Learning berbantuan Geogebra}

Untuk mengetahui respon siswa terhadap pembelajaran dengan menggunakan pendekatan Saintifik model Problem based Learning berbantuan Geogebra peneliti menggunakan angket sebagai instrumen. Angket tersebut terdiri dari 30 pertanyaan yang bersifat positif dan negatif. Pada umumnya, siswa bersikap positif atau baik terhadap pembelajaran matematika model pembelajaran Problem based Learning berbantuan Geogebra yaitu dengan nilai rata-rata sebesar 3,9. Selain dihitung secara keseluruhan, skala sikap siswa juga dianalisis berdasarkan tujuh indikator. Indikator-indikator tersebut dapat dilihat dari tabel 3 berikut:

Tabel 3. Data Skala Sikap

\begin{tabular}{lcc}
\hline Indikator & $\begin{array}{c}\text { Banyaknya } \\
\text { pernyataan }\end{array}$ & Rata-rata \\
\hline Terhadap Materi Geometri & 4 & 3,8 \\
Peranan Guru & 4 & 3,7 \\
Aplikasi Geogebra & 2 & 3,6 \\
PBL Pendekatan Saintifik & 9 & 3,9 \\
Interaksi Teman & 4 & 3,9 \\
\hline
\end{tabular}




\begin{tabular}{ccc}
\hline Kemampuan Spasial & 4 & 4,1 \\
LKS & 3 & 3,9 \\
\hline
\end{tabular}

Dari Tabel 3 diperoleh data skala sikap siswa terhadap ketujuh indikator, yaitu terhadap materi geometri, peranan guru, aplikasi Geogebra, pendekatan saintifik model PBL, interaksi teman, kemampuan spasial dan lembar kerja siswa (LKS). Sikap siswa terhadap materi geometri mendapatkan nilai rata-rata sebesar 3,8 dari 4 pernyataan, maka sikap siswa bersifat positif. Sikap siswa terhadap peranan guru mendapatkan nilai sebesar 3,7 dari 4 pernyataan, maka sikap siswa bersifat positif. Selanjutnya dilihat dari aplikasi Geogebra yang digunakan sebagai media pembelajaran mendapatkan nilai rata-rata sebesar 3,6 dari 2 pernyataan, maka sikap siswa bersifat positif. Begitupun terhadap model pembelajaran PBL pendekatan saintifik, interaksi teman, kemampuan spasial dan LKS yang memiliki nilai ratarata berturut-turut 3,9, 3,9, 4,1, dan 3,9 menyatakan bahwa sikap siswa bersifat positif. Dengan demikian dapat diperoleh kesimpulan bahwa sikap siswa terhadap pembelajaran geometri dengan pendekatan Saintifik model Problem based Learning berbantuan Geogebra berkesan positif.

\section{KESIMPULAN}

Berdasarkan hasil penelitian dan anlisis terhadap pembelajaran matematika dengan model Problem based Learning berbantuan Geogebra untuk meningkatkan kemampuan spasial matematis siswa terhadap materi geometri di MA Al-Hanif kelas XI IIS dengan materi Geometri, maka kesimpulan yang diperoleh adalah pembelajaran matematika dengan model Problem based Learning berbantuan Geogebra dapat meningkatkan kemampuan spasial matematis siswa. Selain itu, aktivitas siswa dan guru terhadap model Problem based Learning berbantuan Geogebra dapat berjalan dengan efektif dan kondusif. Respon siswa dalam pembelajaran geometri dengan pendekatan Saintifik model Problem based Learning berbantuan Geogebra umumnya menghasilkan kesan yang positif.

\section{UCAPAN TERIMAKASIH}

Terima kasih kepada santri kelas XI, Guru Matematika, Kepala Sekolah MA Al-Hanif, FKIP Universitas Suryakancana pihak-pihak lainnya yang telah membantu dalam kegiatan penelitian yang telah dilaksanakan. 


\section{REFERENSI}

Aisyah, N. (2016). Pengaruh Model Problem Based Learning Berbantuan Software Geogebra Terhadap Kemampuan Pemecahan Masalah Matematika. Jurnal Kajian Pendidikan Matematika, 1(2), 159-168.

Aqib, Z. (2006). Penelitian Tindakan Kelas. Bandung: Yrama Widya.

Karso. (1993). Dasar-Dasar Pendidikan MIPA. Jakarta: Universitas Terbuka-Depdikbud.

Lestari, K.E. \& Yudhanegara, M.R. (2015). Penelitian Pendidikan Matematika. Bandung: PT. Refika Aditama.

Mulyadi, Riyadi, \& Subanti, S. (2015). Analisis Kesalahan Dalam Menyelesaikan Soal Cerita Pada Materi Luas Permukaan Bangunruang Berdasarkan Newman's Error Analysis (Nea) Ditinjau Dari Kemampuan Spasial. Jurnal Elektronik Pembelajaran Matematika, 3(4), 370-382.

Permatasari, E.A. (2014). Implementasi Pendekatan Saintifik dalam Kurikulum 2013 pada Pembelajaran Sejarah. Jurnal IJHE. 3(1), 11-16.

Nopiyani, D., Turmudi, T., \& Prabawanto, S. (2018). Penerapan Pembelajaran Matematika Realistik Berbantuan GeoGebra untuk Meningkatkan Kemampuan Komunikasi Matematis Siswa SMP. Mosharafa: Jurnal Pendidikan Matematika, 5(2), 45-52.

Saerah, S. (2016). Peningkatan Kemampuan Pemahaman Matematis Siswa Kelas VII Melalui Model Pembelajaran Kooperatif Tipe Make a Match. Artikel tidak diterbitkan. Cianjur: FKIP Universitas Suryakancana.

Siswanto, R. D. (2016). Asosiasi Antara Kemampuan Geometri Spasial Dengan Kemampuan Berpikir Kreatif Matematis Siswa. KALAMATIKA Jurnal Pendidikan Matematika, 1(2), 141-146.

Sugiarni, R. (2015). Implementasi Asesmen Kinerja Dalam Pbl Untuk Meningkatkan Pemecahan Masalah Matematik. Jurnal PRISMA, 24-37.

Syahputra, E. (2013). Peningkatan Kemampuan Spasial Siswa Melalui Penerapan Pembelajaran Matematika Realistik. Jurnal Cakrawala Pendidikan, 353-364. 
Sugiarni, Alghifari \& Ifanda, 102 